\title{
The Possible Application of He-Ne Laser for Dental Plaque Control
}

\author{
Hayato OKAMOTO, Tatsuo IWASE, Toshiyuki SAITO* \\ and Toshio MORIOKA** \\ Maidashi 3-1-1, Higashi-Ku, Fukuoka 812, Japan \\ Department of Preventive Dentistry, Faculty of Dentistry, \\ Kyushu University \\ * Department of Health and Environment, Saga Prefecture \\ ${ }^{* *}$ Department of Dental Hygiene, Ogaki Women's College
}

\begin{abstract}
A possibility of the He-Ne laser application for human dental plaque control was investigated. Twenty adult volunteers participated in this experiment. One of the premolar teeth on one side of a subject was irradiated by the He-Ne laser for $3 \mathrm{~min}$., once a day, for 3 days, at an output power of $20 \mathrm{~mW}$, while one of the premolar teeth on the other side was left unirradiated as a control. The number of cultivable plaque bacteria was found to be reduced by He-Ne laser irradiation when dental plaque was stained with methylene blue-based plaque-disclosing dye. No similar decrease in cultivable bacteria was observed when the laser irradiation or the plaque-disclosing dye alone was used. From these results, the photodynamic killing mediated by He-Ne laser irradiation was shown to affect oral bacteria in vivo, and the potential application of this new modality for dental plaque control is discussed.
\end{abstract}

Key words : He-Ne laser, dental plaque control, in vivo, dye, photodynamic action

\section{Introduction}

The most prevalent diseases in the oral region are dental caries and periodontal diseases. It is now widely recognized that the most important cause of both diseases is dental plaque bacteria and the removal of such bacteria prevents the incidence, progress and relapse of those diseases. The most popular method of plaque control is to mechanically remove the dental plaque by means of a tooth brush.

We have previously reported that mutans strep- tococci, used as a representative of oral bacteria, were briefly killed by He-Ne laser irradiation [1]. The number of investigations into the effects of low-power lasers has been extremely limited [1-3]. There have been several reports on the effects of laser irradiation on microorganisms [1-9], but most of these reports have been concerned with the bactercidal action of high-power lasers which arises from the heat they produce. However, such high-power lasers cannot be applied for plaque 
control, because the heat produced would adversely affect either the dental pulp or the periodontal tissue. If plaque bacteria could be killed by a low-power laser beam, it would be possible to prevent plaque accumulation and subsequent diseases.

The aim of the present study is to explore the photodynamic killing effect of a low-power $\mathrm{He}-\mathrm{Ne}$ laser on plaque bacteria in vivo, as a first step towards the clinical application of this laser.

\section{Materials and Methods}

Laser system. A He-Ne continuous wave gas laser (KHL-50, NEC, Tokyo, Japan) which radiates a $632.8 \mathrm{~nm}$ beam was used. The laser device was coupled to a glass optical fiber, $2 \mathrm{~mm}$ in diameter. The output power as measured by a power meter (SCIENTECH 361, Boulder, CO, USA) was $20 \mathrm{~mW}$. By defocusing, it was possible for the irradiation area to cover the surface of one tooth. The distance from the tip of the fiber to the tooth surface was $1.5 \mathrm{~cm}$.

Experimental design. Twenty adult voluntees aged 24 to 34 years old were used in these experiments. At the beginning of each experiment, the tooth surfaces of the subject were mechanically cleaned by a dentist. A pair of premolars which had no prosthesis on the buccal surfaces was selected in each subject. Prior to each session of irradiation, the dental plaque on the teeth of both sides was stained with a plaque-disclosing dye (MT750, Murakami Lab., Fukuoka, Japan), which contained methylene blue. Neither brushing of the teeth nor dental flossing was performed during the period of the experiment. The tooth on one side was irradiated by the $\mathrm{He}-\mathrm{Ne}$ laser for $3 \mathrm{~min}$., once a day, for 3 days, while the corresponding tooth on the other side was left unirradiated as a control. The effect of laser irradiation without the plaque-disclosing dye and that of the plaquedisclosing dye alone were also examined. For these controls, the tooth on one side of a subject was irradiated without staining or else was stained with no irradiation, while the one on the other side was left untreated for 3 days. After all the experiments were finished, the supragingival dental

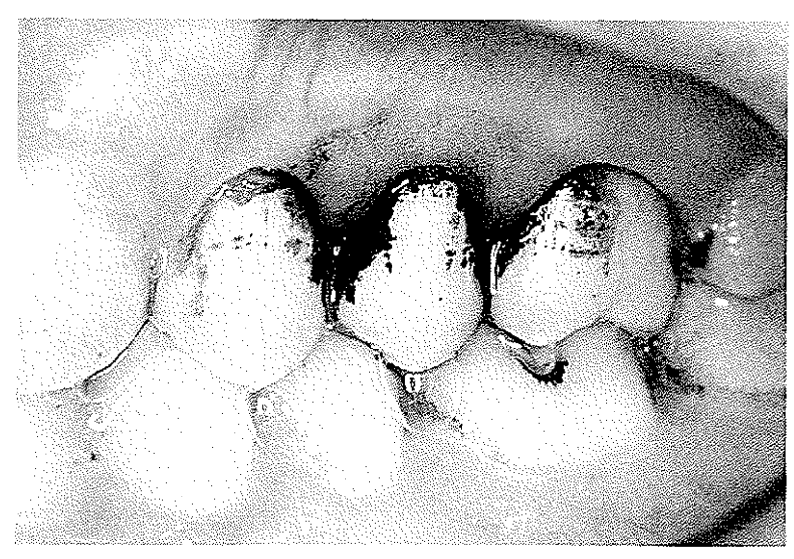

a

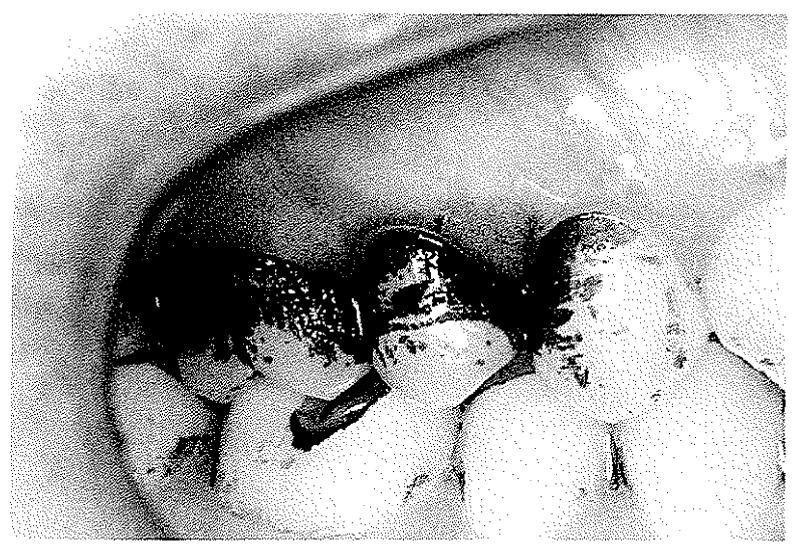

$\mathrm{b}$

Fig. 1 The suppression of dental plaque deposition on human upper second premolar tooth by laser-mediated photodynamic action.

a, irradiated side ; b, unirradiated side.

plaque deposited on the buccal surface involving the mesial and distal angles of the test tooth was removed as completely as possible with a scaler under semi-dry conditions. The sampled dental plaque was then dispersed in sterile physiological saline by ultrasonic irradiation using a Model W-225R sonicator (Heat Systems-Ultrasonics, Inc., Plainview, NY, USA) at $20 \mathrm{KHz}$ and a power output of $55 \mathrm{~W}$ for 60 seconds. Aliquots of these dilutions were plated on a brain-heart infusion (BBL, Cockeysville, MD, USA) agar, and the number of colonies was counted after anaerobic incubation under an atmosphere consisting of $90 \% \mathrm{~N}_{2}, 5 \%$ $\mathrm{CO}_{2}$ and $5 \% \mathrm{H}_{2}$ at $37^{\circ} \mathrm{C}$ for $48 \mathrm{hr}$.. The paired t-test and Wilcoxon test were used for statistical comparisons.

\section{Results}

To assess the possibility of potential clinical ap- 
Table 1. The number of cultivable bacteria found in dental plaque on the photochemically treated tooth surface

\begin{tabular}{|c|c|c|c|c|}
\hline Case & $\begin{array}{l}\text { Irradiated* } \\
\operatorname{side}(I)\end{array}$ & $\begin{array}{l}\text { Unirradiated* } \\
\operatorname{side}(U)\end{array}$ & $\%$ & Decrease ** \\
\hline 1 & 26 & 322 & & 91.9 \\
\hline 2 & 55 & 414 & & 86.7 \\
\hline 3 & 92 & 305 & & 69.8 \\
\hline 4 & 77 & 128 & & 39.8 \\
\hline 5 & 83 & 275 & & 69.8 \\
\hline 6 & 90 & 770 & & 88.3 \\
\hline 7 & 2 & 188 & & 98.9 \\
\hline 8 & 90 & 680 & & 86.8 \\
\hline 9 & 96 & 157 & & 38.9 \\
\hline 10 & 126 & 305 & & 58.7 \\
\hline 11 & 197 & 704 & & 72.0 \\
\hline 12 & 196 & 885 & & 77.9 \\
\hline 13 & 27 & 193 & & 86.0 \\
\hline 14 & 61 & 130 & & 53.1 \\
\hline 15 & 76 & 848 & & 91.0 \\
\hline 16 & 240 & 544 & & 55.9 \\
\hline 17 & 28 & 240 & & 88.3 \\
\hline 18 & 20 & 52 & & 61.5 \\
\hline 19 & 38 & 272 & & 86.0 \\
\hline 20 & 41 & 185 & & 77.8 \\
\hline
\end{tabular}

*. $\times 10^{4} / \mathrm{ml}$

***. $\mathrm{P}<0.001$ (paired t-test)

of Decrease, U-I/U 100

Table 2. The number of cultivable bacteria found in dental plaque on the tooth surface treated with laser irradiation alone

\begin{tabular}{c|c|c|c}
\hline Case & $\begin{array}{c}\text { Irradiated * } \\
\text { side( I ) }\end{array}$ & $\begin{array}{l}\text { Unirradiated * } \\
\text { side(U) }\end{array}$ & $\%$ Decrease ** \\
\hline 1 & 164 & 196 & 16.3 \\
2 & 131 & 147 & 10.9 \\
3 & 568 & 578 & 1.7 \\
4 & 204 & 314 & 35.0 \\
\hline
\end{tabular}

*, $\times 10^{4} / \mathrm{ml}$

$* *$, No significance (Wilcoxon test)

"Decrease, U-I/UX100

Table 3 . The number of cultivable bacteria found in dental plaque on the tooth surface treated with plaque-disclosing dye (MT750) alone

\begin{tabular}{c|c|c|c}
\hline Case & $\begin{array}{c}\text { Stained } \\
\text { side( S })^{*}\end{array}$ & $\begin{array}{c}\text { Unstained * } \\
\text { side( U) }\end{array}$ & $\%$ Decrease** \\
\hline 1 & 184 & 321 & 42.7 \\
2 & 287 & 415 & 30.8 \\
3 & 290 & 306 & 5.2 \\
4 & 126 & 207 & 39.1 \\
\hline
\end{tabular}

$*, \times 10^{4} / \mathrm{ml}$

$* *$, No significance (Wilcoxon test)

Decrease, U-S/Ux100 
plication for the $\mathrm{He}-\mathrm{Ne}$ laser in human dental plaque control, the photodynamic killing effect of dental plaque bacteria was examined using the plaquedisclosing dye MT750 as a sensitizer. Figure 1 shows the dental plaque on the second premolar tooth of a subject which was stained on the $3 \mathrm{rd}$ day of the experiment. Clearly, the plaque on the irradiated surface of the tooth was found to occupy a smaller area than that which formed on the unirradiated surface. Table 1 shows the number of cultivable bacteria in the dental plaque on both irradiated and unirradiated tooth surfaces. In all cases, the number of cultivable bacteria in the dental plaque on the irradiated tooth surface was smaller than the number on the unirradiated control surface on the $3 \mathrm{rd}$ day of the experiment. The rate of decrease ranged from $98.9 \%$ to $38.9 \%$, with an average of 74. $0 \%$. The difference was highly significant ( $P$ $\langle 0.001$ ) according to the paired $t$-test. Table 2 shows the effect of $\mathrm{He}-\mathrm{Ne}$ laser irradiation without dye on plaque bacteria. In all cases, the number of cultivable bacteria in the plaque exposed to the laser was only slightly less than the number on the unirradiated control surface with no statistical difference between both sides. The effect of the plaquedisclosing dye on plaque bacteria is shown in Table 3. Even when using the dye alone, the number of cultivable bacteria in the plaque was smaller than in the control without the dye with no statistical difference between both sides.

\section{Discussion}

In our previous study, when mitis salivarius (MS) agar plates inoculated with mutans streptococci were irradiated with the He-Ne laser, growth-inhibitory zones were clearey observed. Since MS agar contained crystal violet, it was thought that photodynamic action was involved in the formation of the growth-inhibitory zones. Indeed, no inhibitory zone was formed with laser irradiation alone. Furthermore, when we examined potassium ion leakage from the bacterial cells in order to find out whether any damage to the cell membrane was caused by $\mathrm{He}-\mathrm{Ne}$ laser irradiation, it was already evident even following $2 \mathrm{~min}$. of irradiation in the presence of crystal violet [1]. Thus, since no such action was seen without dye, it is reasonable to assume that the $\mathrm{He}-\mathrm{Ne}$ laser-mediated bactericidal effect is due to the so-called photodynamic action, involvlng singlet oxygen generated through energy transfer of the light-excited dye molecules. Singlet oxygen may also bring about oxidative damage to bacterial DNA or the cell membrane or both, causing cell death [10].

On the basis of the above statements, the photodynamic action of the He-Ne laser against oral plaque bacteria was examined in vivo in an attempt to apply it to plaque control. The number of culti. vable plaque bacteria following laser irradiation was determined by means of the viable counting of colonies because the assessment of adherence of dental plaque to tooth surface on a photograph was still poorly understood regarding the activity of plaque bacteria. By using the methylene blue-based plaque-disclosing stain and He-Ne laser irradiation jointly, a substantial decrease in the number of cultivable bacteria present in dental plaque was brought about. The effect of various dyes necessary to bring about a laser-mediated photodynamic killing against Streptococcus sobrinus AHT has been studied in our laboratory [1]. Of the various dyes screened, when blue or purple dyes were mainly used together with $\mathrm{He}-\mathrm{Ne}$ laser irradiation, a killing effect was manifested. This is reasonable since the red light of the He-Ne laser is efficiently absorbed by blue dyes [11]. Due to the fact that the red and yellow dyes do not absorb the red light of the He-Ne laser, the photodynamic killing effect of the laser may be lost. These results suggest the possibility that dental plaque can be controlled by the pholodynamic action of the $\mathrm{He}-\mathrm{Ne}$ laser. Some dyes, such as methylene blue, are well known to have a bactericidal effect when used alone. By using the He-Ne laser alone, the number of cultivable bacteria in dental plaque was reduced only slightly. Iwase et al. observed the inhibitory effect of He-Ne laser irradiation alone on dental plaque deposition in hamsters in vivo, when used for $2 \mathrm{~min}$, every day [2]. These phenomena may suggest that the He-Ne laser has some other effects 
besides the effect of killing plaque bacteria, which should thus be further studied in the future.

It is impossible to control all intraoral plaque by the He-Ne laser, because a laser beam can irradiate only a small area. However, by means of changing the output power and defocusing, we can regulate the size of the irradiated area and the power density, choosing that which is best suited for the required purpose. Moreover, judging from the results in these fundamental experiments, one irradiation of the laser lasting for $3 \mathrm{~min}$. can be effective in killing bacteria. Therefore, although this method may not be suitable for routine oral hygiene, it would be suitable for professional plaque control in a clinical setting. This method has the following advantages. Firstly, we can direct a laser beam to a desired site in a narrow oral cavity using an optical fiber and raise the energy density with a lens. Secondly, because the He-Ne laser beam is harmless to the human body and has tissue-penetrability, it may be possible to irradiate oral bacteria in the periodontal pocket through the gingiva. Moreover, the detection and destruction of dental plaque can be effected in consecutive operations. Lastly, the device is compact enough to be suitable for chair-side use. These merits suggest that the $\mathrm{He}-\mathrm{Ne}$ laser may be potentially useful for professional plaque control. Therefore, $\mathrm{He}-\mathrm{Ne}$ laser application for plaque control seems worthy of further study.

\section{References}

1. Okamoto H, Iwase T, Morioka T.: Dye-mediated bactericidal effect of $\mathrm{He}-\mathrm{Ne}$ laser irradiation on oral microorganisms. Lasers Surg Med, $12: 450-458,1992$.

2. Iwase T,Saito T, Nara Y,Morioka T. Inhibitory effect of He-Ne laser on dental plaque deposition in hamsters. J Periodont Res, 24:282-283, 1989.

3. Macmillan JD, Maxwell WA, Chichester CO.: Lethal photosensitization of microorganisms with light from a continuous-wave gas laser. Photochem Photobiol, 5 : 555-565, 1966.

4. Schultz RJ, Harvey GP, Fernandez-Beros
ME, Krishnamurthy S, Rodriguez JE, Cabello F.: Bactericidal effects of the neodymium: YAG laser: In vitro study. Lasers Surg Med, $6: 445-448,1986$.

5. Klein E, Fine S, Ambrus J, Cohen E, Neter E, Ambrus C, Bardos T, Lyman R.: Interaction of laser radiation with biologic systems. III. Studies on biologic systems in vitro. Fed Proc, $24: 104-110,1965$.

6. Zakariasen KL, Dederich DN, Tulip J, DeCoste S, Jensen SE, Pickard MA.: Bactericidal action of carbon dioxide laser radiation in experimental dental root canals. Can J Microbiol, 32 : 942946, 1986.

7. Adrian JC, Gross A.: A new method of sterilization : the carbon dioxide laser. J Oral Pathol, $8: 60-61,1979$.

8. Hooks TW, Adrian JC, Gross A, Bernier WE.: Use of the carbon dioxide laser in sterilization of endodontic reamers. Oral Surg, $49: 263-$ $265,1980$.

9. Keates RH, Drago PC, Rothchild EJ.: Effect of excimer laser on microbiological organism s. Ophthalmic Surg, $19: 715-718,1988$.

10. Martin JP, Logsdon N.: The role of oxygen radicals in dye-mediated photodynamic effects in Escherichia coli B. J Biol Chem, 262 : 72137219, 1987.

11. Morioka T. ed.: Laser in Dental Medicine. Tokyo: Ishiyaku Publishers, Inc. 50. 1986. 